\title{
Psicologia Forense em Portugal: Uma história de responsabilidades e desafios
}

RUI ABRUNHOSA GONÇALVES (*)

\section{INTRODUÇÃO}

No quadro das ligações entre a Psicologia e a Justiça, avulta desde há muito tempo a disciplina de Psicologia Forense, que tem como objecto a avaliação do comportamento humano nos vários contextos que a Justiça lhe franqueia, sobretudo numa perspectiva pré-sentencial - funcionando deste modo como elemento de ajuda à tomada de decisão judicial - mas também como auxiliar de processos de intervenção operados em actores do sistema judicial, quer se trate de agressores, vítimas, testemunhas ou "funcionários" desse mesmo sistema (e.g., magistrados, polícias, peritos, ...). Distingue-se assim de um âmbito mais lato que é o da Psicologia Jurídica ou o da Psicologia Legal e de outros mais restritos como são, por exemplo, a Psicologia Penitenciária ou a Psicologia Criminal (e.g., Fariña, Arce, \& Novo, 2005), podendo ser definida como "a aplicação dos princípios e procedimentos da avaliação psicológica à resolução de questões surgidas em contextos legais" (Nicholson, 1999, p. 121), nomeadamente nos tribunais.

Este âmbito mais restrito, parece colocar na Psicologia Forense quase que um papel "legitimador" da Justiça, já que é ao psicólogo forense que, muitas vezes, são pedidas respostas para elucidar os decisores judiciais. Num outro

(*) Escola de Psicologia, Universidade do Minho, Braga, Portugal; e-mail: rabrunhosa@psi.uminho.pt. polo, é também sobre ele que se depositam as responsabilidades de um esclarecimento das motivações que levaram determinados indivíduos a cometer crimes ou não, assim como a averiguação da veracidade e da credibilidade dos depoimentos de vítimas, arguidos ou outros intervenientes nos processos judiciais ou cíveis. Concomitantemente, percebe-se que o trabalho de um psicólogo forense apresenta vários riscos e outras tantas responsabilidades.

Neste texto procuraremos reflectir sobre o desenvolvimento da Psicologia Forense entre nós, alertando para a importância cada vez maior que o trabalho dos psicólogos nos tribunais vai assumindo, e apresentando alguns dados decorrentes de investigações recentes, que não só ilustram essa relevância como ainda alertam para a responsabilidade cada vez maior que vamos tendo. Mas como não há responsabilidade que não envolva risco, dedicar-nos-emos também a elencar alguns dos problemas para que devemos estar atentos, no sentido da salvaguarda da profissão e de uma postura ética e deontológica adequada.

Num primeiro momento, referiremos alguns antecedentes históricos importantes que caracterizaram os primórdios e o desenvolvimento inicial da Psicologia Forense em Portugal, para de seguida nos centrarmos nos contributos mais recentes ilustrados com investigação recolhida, sobretudo no âmbito do funcionamento da Unidade de Consulta de Psicologia da Justiça da Universidade do Minho, que completou em 2008 dez anos de existência. 


\section{A HISTÓRIA MAIS ANTIGA}

As ligações entre a Psicologia e a Justiça em Portugal registam uma história longa e profícua que ultrapassa já um século (cf. Gonçalves, 1996). Nesse percurso destacam-se algumas contribuições marcantes. Assim, Ferreira Deusdado, em 1890, publica "Essais de Psychologie Criminelle" onde afirmava o seu desacordo com as explicações lombrosianas da criminalidade, chamando a atenção para a importância dos factores sociais na génese do crime. Em 1918, Luiz Viegas procede à transformação do Posto Anthropométrico do Porto de que era Director, na "Repartição de Antropologia Criminal, Psicologia Experimental e Identificação Civil do Porto", facto que constitui a primeira menção oficial nacional, onde a Psicologia surge ligada aos contextos de Justiça e, em particular, à avaliação da criminalidade. Por seu lado, é de destacar o empenho e dinâmica imprimida por Luiz de Pina na direcção do Instituto de Criminologia do Porto que redunda, entre outros aspectos, no aparecimento de vários estudos envolvendo a aplicação de provas psicológicas - sobretudo o Rorschach a delinquentes recluídos (cf. Pina, 1960). Finalmente, destaque-se a referência à Psicologia do Testemunho através dos contributos de Carrington da Costa (1954 a,b).

Importa igualmente referir, mas agora pela negativa, que a década de sessenta é aquela em que a componente da contribuição psicológica na área da Justiça entra em acentuado declínio, pelo menos ao nível da apresentação de estudos e investigações, quando tudo levaria a supor um incremento de produção face à tendência registada nos períodos anteriores. A isso não será estranho o lento agonizar em que mergulharam os Institutos de Criminologia de Lisboa, Porto e Coimbra, que se reflectiu na revista que lhes dava suporte - o Boletim da Administração Penitenciária e dos Institutos de Criminologia (BAPIC), de publicação semestral - cuja periodicidade começa a evidenciar problemas que se acentuarão na década de 70 , sendo o seu último número publicado em 1981¹. Nem mesmo

${ }^{1}$ Esta última edição do BAPIC correspondia a um número quádruplo (quatro semestres: 1980-81), com menos de 200 páginas e com uma tiragem de apenas 300 exemplares. depois de um novo decreto refundador (Lei 96/95 de 10/5) os Institutos de Criminologia foram reactivados.

Porém, curiosamente, é nos anos sessenta que o Instituto Superior de Psicologia Aplicada (ISPA) inicia em Portugal o ensino da Psicologia a nível superior, sendo aliás de um licenciado dessa Escola que aparecerá pela primeira vez um texto assinado por um psicólogo (Alves, 1979) nas páginas do já referido BAPIC. Posteriormente, no final dos anos setenta, surgem os cursos oficiais de Psicologia nas Universidades portuguesas (Coimbra, Lisboa e Porto), com os primeiros licenciados a sair já na década seguinte. Nos seus curricula, porém, e à semelhança do ISPA, nenhuma menção era feita à ligação entre a Psicologia e a Justiça.

Este período encerra-se assim, a nosso ver, de forma algo paradoxal já que, se de um lado a Psicologia surge pela primeira vez como uma formação académica autónoma através do ISPA e posteriormente das Faculdades das Universidades Públicas, por outro dilui-se praticamente o seu investimento e aplicação na área da Justiça, em claro desacerto com o trabalho desenvolvido até ao final dos anos sessenta e com a própria evolução além-fronteiras a começar logo pela vizinha Espanha (e.g., Bajet \& Royo, 1992).

\section{A HISTÓRIA MAIS RECENTE}

É na década de oitenta que se assiste à progressiva afirmação da Psicologia portuguesa como ciência e profissão marcadamente vocacionadas para a investigação e intervenção sobre os problemas da sociedade (Almeida, 1993). Assim, e à medida que se ia cimentando o seu peso institucional em áreas que desde sempre foram consideradas como mais tradicionais nesta ciência (e.g., clínica, educação e trabalho/organizações), irrompiam, aqui e ali, sinais premonitores de novos domínios a explorar que, embora já bem implantados noutros países, não tinham ainda logrado obter entre nós, a necessária projecção. Era o caso da Psicologia da Saúde, da Psicologia do Desporto, da Psicologia Ambiental ou da Psicologia Comunitária, para citar só alguns. E também foi o caso da Psicologia da Justiça (e.g., Almeida, 1993; Gonçalves, 1993). 
De facto, os anos oitenta marcam uma profunda viragem nos contributos nacionais da Psicologia para os contextos de Justiça, sendo de realçar que este movimento foi feito nos dois sentidos, isto é, a Psicologia procurou a Justiça mas esta também foi ao encontro daquela. Retomava-se assim uma ligação antiga que os últimos vinte anos tinham aparentemente deixado cair no olvido. Relembremos pois alguns dos aspectos mais marcantes dessa viragem.

Em primeiro lugar, destacaríamos a aprovação de uma nova Legislação Penal e Processual Penal em 1982 e 1987, respectivamente, em que é particularmente realçado o papel do saber e prática psicológicas como coadjuvante do saber jurídico, sendo nalguns casos explicitamente veiculada a necessidade da presença dos psicólogos e do seu saber específico (e.g., perícias de personalidade). Simultaneamente, surge o Instituto de Reinserção Social (actualmente Direcção Geral de Reinserção Social), instituição destinada inicialmente ao auxílio na execução de medidas alternativas à pena de prisão e medidas de flexibilização da pena de prisão, para além do apoio directo aos tribunais em casos cíveis e penais e que mais tarde abarcaria a tutela dos menores. Com tais tarefas pela frente, esta instituição recrutará para os seus quadros, a par de outros técnicos, um elevado número de psicólogos, tendo-se então constituído como o maior empregador oficial de psicólogos em Portugal $^{2}$. Este esforço de renovação dos quadros profissionais do Estado, através da entrada de psicólogos foi igualmente levado a cabo pela Direcção Geral dos Serviços Prisionais e pela então existente Direcção Geral dos Serviços Tutelares de Menores. Num outro plano, registese o aparecimento, em publicações periódicas da área da Justiça, oriundas de várias instituições, de um número assinalável de textos assinados por psicólogos ${ }^{3}$, para além de um conjunto de obras

2 De acordo com dados oficiais que nos foram facultados, pela então Vice-presidente do IRS, Dra. Fernanda Farinha, existiam no início de 1996 no IRS/DGRS, 210 Técnicos Superiores licenciados em Psicologia (dos quais 10 em cargos dirigentes), representando uma percentagem de $29 \%$ ao nível das Equipas de Reinserção Social.

3 "Revista de Investigação Criminal" (Directoria do Porto da Polícia Judiciária), "Polícia e Justiça” (Escola da Polícia Judiciária/Instituto Superior de Polícia Judi- colectivas, quase sempre resultantes da realização de congressos (e.g., Barroso \& Gonçalves, 1992; Gonçalves, Machado, Sani, \& Matos, 1999; Silva, Barroso, Cóias, \& Costa, 1995). Finalmente, assiste-se à institucionalização no quadro da formação académica em Psicologia de áreas curriculares de pré-graduação emanantes deste domínio, primeiro na Faculdade de Psicologia e de Ciências da Educação do Porto em 1985 (Psicologia do Comportamento Desviante; e.g., Agra, 1986), depois em 1991 no Instituto de Educação e Psicologia da Universidade do Minho (Psicologia da Justiça e da Reinserção Social; e.g., Gonçalves, 1996) e posteriormente (1997) na Universidade Lusófona (Psicologia Criminal e do Comportamento Desviante). Adicionalmente, surgem pós-graduações em Psicologia Legal (ISPA, 1991) e Criminologia (FPCE-UP, 1992), entre outras.

Estes três vectores de implantação da Psicologia da Justiça - inserção de profissionais no mercado de trabalho, produção científica e formação académica - que se desenvolveram e consolidaram em Portugal ao longo dos anos oitenta e noventa do século passado, auguravam uma estabilidade que permitiu uma expansão controlada a domínios até aí por explorar, criando as condições para que nos anos subsequentes se assistisse a uma consolidação de saberes e práticas, de que a Psicologia Forense tem sido sem dúvida um dos expoentes mais nítidos.

\section{A PSICOLOGIA FORENSE EM PORTUGAL}

\section{Certezas e responsabilidades}

A necessidade de introduzir processos de avaliação adequados e credíveis em muitos contextos de interface entre a Psicologia e a

ciária e Ciências Criminais) e "Temas Penitenciários" (Direcção Geral dos Serviços Prisionais). Paralelamente, surgem textos que poderíamos enquadrar no contexto da Psicologia da Justiça, publicados em várias revistas (e.g., Psicologia, $n^{\circ} 4$, 1981; Raiz \& Utopia $n^{\circ}$ 17/18/19, 1981; Análise Psicológica $n^{\circ}$ 3/4, 1986; Psiquiatria Clínica, $n^{\circ}$. 9, 1988; Jornal de Psicologia, $\left.n^{\circ} 1,1989\right)$. Refira-se ainda a "Infância e Juventude" (Direcção-Geral dos Serviços Tutelares de Menores/Instituto de Reinserção Social) que foi a publicação periódica mais antiga nesta área e onde textos de psicólogos sempre tiveram acolhimento. 
Justiça, para além de ser um dado desde há muito adquirido, é também uma questão de grande responsabilidade. Começando por tarefas mais tradicionais como a selecção de agentes policiais, desde logo se percebe a importância de que se reveste esse processo em ordem a escolher os mais capazes e mais competentes (e.g., Soeiro, 1999). Num outro plano, assinalese o trabalho que é exigido aos psicólogos que trabalham nas Comissões de Protecção de Crianças e Jovens para poderem detectar atempadamente os menores em risco e propor o encaminhamento que melhor salvaguarde os seus interesses bem como os das respectivas famílias e da sociedade em geral. No quadro das instituições que albergam menores ou adultos, registe-se também a necessidade de proceder a avaliações criteriosas tendo em vista a emissão de pareceres que poderão culminar na alteração da medida que, no limite, levará à libertação do sujeito. E naturalmente, em fases pré-sentenciais, seja de processos penais ou cíveis, o labor do psicólogo forense é essencial como auxiliar à tomada de decisão judicial.

Talvez por tudo isso, o acervo de obras publicadas entre nós nos últimos anos, em que são visíveis as preocupações em torno de uma melhor fundamentação teórica e empírica dos procedimentos de avaliação psicológica forense, tem sido marcante (e.g., Fonseca, 2004, 2009; Fonseca, Simões, Simões, \& Pinho, 2006; Gonçalves \& Machado 2005; Machado \& Gonçalves, 2003, 2008; Sani, 2002). Tal demonstra, a nosso ver, uma preocupação ética louvável para tentar partilhar o saber e o saber-fazer com o "público" de profissionais de Psicologia que cada vez mais se vê confrontado com pedidos vindos dos Tribunais, aos quais poderão ter dificuldade em responder, dada a sua eventual impreparação na área da psicologia forense.

Desde 1998, que existe no âmbito do Serviço de Consulta Psicológica e Desenvolvimento Humano da Universidade do Minho, uma Unidade de Consulta em Psicologia da Justiça (UCPJ). Nesta Unidade, para além da intervenção junto de vítimas ou de ofensores, tem sido desenvolvida desde a primeira hora um significativo trabalho de realização de exames de psicologia forense a pedido de Tribunais penais e cíveis (cf. Caridade, Machado, \& Gonçalves, 2006). Na Figura 1 podemos ver a evolução desses pedidos entre 1998 e 2005, sendo certo que nos últimos anos tem-se acentuado a tendência de solicitações em todos os domínios, provavelmente pelo facto de certas problemáticas terem vindo a ganhar maior visibilidade e consciência sociais - casos do abuso sexual e da violência conjugal - ou maior prevalência (e.g., aumento do número de divórcios), na sociedade portuguesa. Deste modo podemos afirmar que o recurso à psicologia forense por parte dos tribunais é uma realidade que tende a expandir-se, sendo disso testemunho, para além dos dados apresentados em relação à UCPJ, as solicitações feitas a outros organismos como o Gabinete de Estudo e Atendimento a Vítimas (cf. Manita, 2005) ou as várias delegações do Instituto Nacional de Medicina Legal (cf. www.inml.mj.pt).

A necessidade de dar resposta a um número crescente de solicitações dos Tribunais, deve conduzir os psicólogos forenses ao questionamento da sua prática, nomeadamente, a verificarem até que ponto as indicações que expressam nos relatórios periciais são ou não acolhidas pelos magistrados. Assim, num primeiro estudo, abarcando as perícias realizadas na UCPJ até 2005 e contemplando 32 processos transitados em julgado 4 , Castro, Martins, Machado, e Gonçalves (2006) verificaram que apenas num caso havia divergência entre a opinião do perito e a decisão judicial ${ }^{5}$, e num outro, referente a um processo de regulação do poder paternal com suspeita de abuso sexual, a decisão judicial é congruente com o parecer dos peritos em matéria de regime de visitas, ainda que considere o abuso não provado (quando a perícia considerava credível essa alegação). Considerando também como elemento de análise a existência ou não de alusões à perícia nos acórdãos de

\footnotetext{
${ }^{4}$ As 32 avaliações periciais envolviam 11 processos de promoção e protecção, 9 de regulação do poder paternal, 7 de credibilidade de alegações de abuso, 3 referentes a arguidos e 2 de violência conjugal (Cf. Castro, Machado \& Gonçalves, 2006).

5 Tratou-se de uma situação de alegação de abuso sexual em menor onde a perícia de psicologia forense ia num sentido contrário ao da perícia médica, tendo o Tribunal optado por esta última, mediante abundante fundamentação.
} 
sentença, os autores verificaram que apenas em 6 casos tal não sucedia, enquanto que em 18 era referida, não só a participação do perito bem como aspectos da perícia eram mencionados e nos 8 acórdãos restantes havia lugar a transcrições directas do relatório pericial.

Mais recentemente, A. Machado (2008) encontra resultados semelhantes, mas agora só com uma amostra $(n=26)$ de processos de regulação do poder paternal que passaram pela UCPJ entre 1998 e 2007, para os quais tinha havido trânsito em julgado. Assim a autora verifica uma concordância total entre conclusões emitidas na perícia e decisão judicial constante dos acórdãos, com mais de três quartos deles $(n=20)$ a transcreverem frases daquelas na sua fundamentação. Num segundo momento do seu estudo, A. Machado (2008) entrevistou 10 magistrados com prática de casos de regulação do poder paternal, destacando-se nas suas respostas o facto de os mesmos atribuírem grande importância à fundamentação, à exaustividade e à objectividade das perícias. Talvez por isso, e reportando-nos à primeira parte do seu estudo, seja referido que só uma pequena percentagem de peritos $(7,7 \% ; n=2)$ fosse chamado a depor em sede de audiência. Assim, os magistrados interrogados neste estudo, consideraram que uma boa perícia é aquela que responde de forma esclarecida, sobretudo, aos seguintes critérios: metodologia (desde a fundamentação à explicação dos instrumentos utilizados); acessibilidade da linguagem (compreensibilidade) e celeridade (realização em tempo útil) (cf. A. Machado, 2008).

Os resultados dos estudos acima referidos, ainda que de âmbito exploratório, alertam-nos para dois aspectos muito importantes. De um lado, a confiança que o poder judicial nos outorga. De outro, a responsabilidade de que somos investidos e os riscos inerentes ao facto de os pareceres e opiniões que emitimos interferirem directamente com a vida das pessoas sobre quem recaem. Por tais razões, cada vez mais, o exercício da psicologia forense não pode ser feito com leveza e muito menos leviandade ou tomado como um conjunto de opiniões gratuitas expelidas a esmo nos órgãos da comunicação social, como se tem vindo a assistir sempre que surgem situações mais mediáticas (e.g., "o caso Esmeralda", "o caso Joana", “o caso Maddie").

FIGURA 1

Avaliações forenses realizadas na UCPJ (1998-2005; $n=154)$ (Caridade et al., 2006)

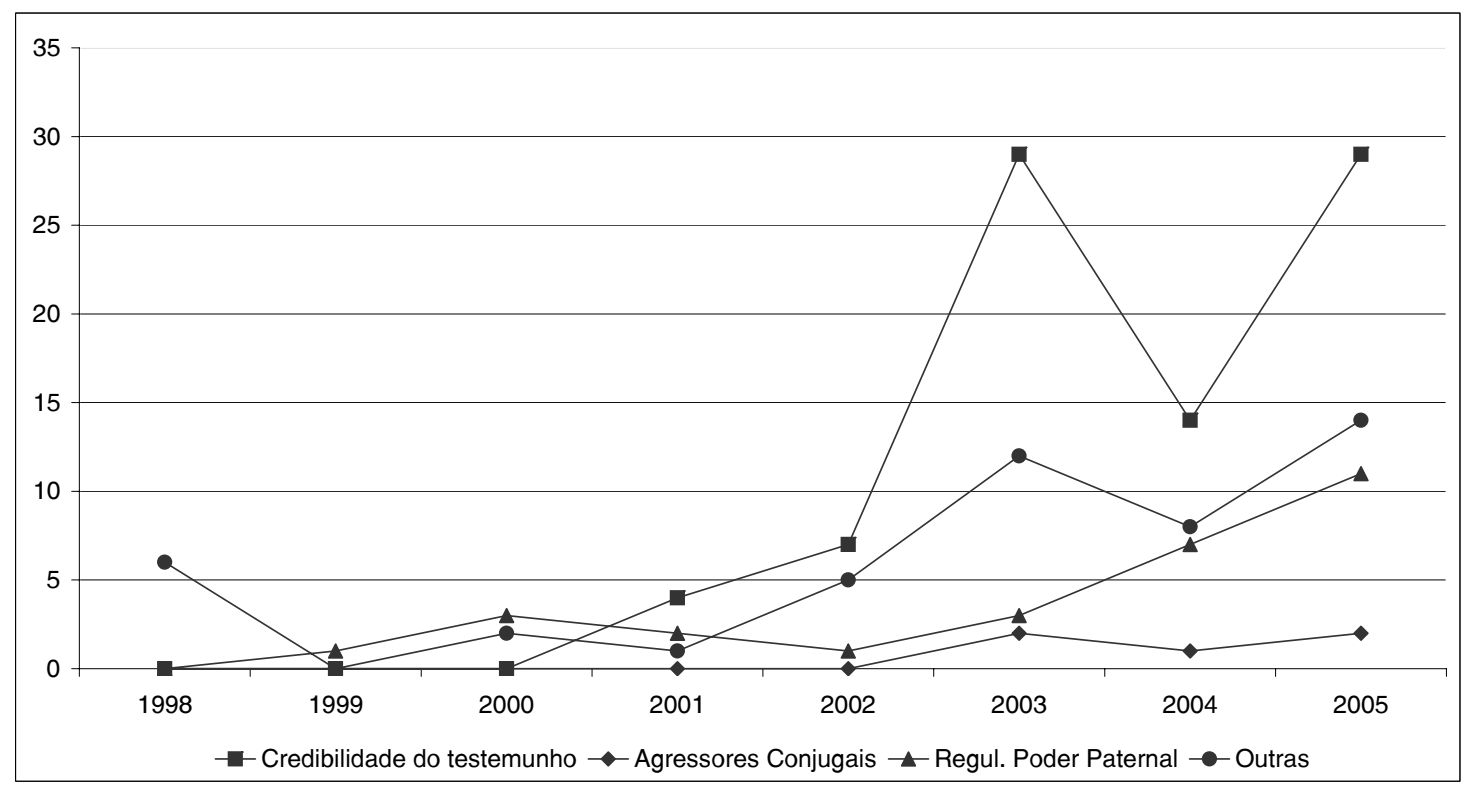




\section{Novos e constantes desafios}

Nos últimos anos, têm-se operado várias transformações legislativas em Portugal - novas leis regulamentadoras da intervenção sobre os menores, novo código penal e processual penal, nova lei do divórcio, entre outras medidas avulsas - que apelam cada vez mais à participação da psicologia forense. Além disso, mais alguns articulados legais fazem directamente apelo à intervenção dos psicólogos, como é o caso da injunção legal que promove a intervenção sobre os agressores conjugais $\left(n^{\circ} 4\right.$ do artigo $152^{\circ}$ do Código Penal), ou da avaliação da "capacidade psíquica" dos portadores de armas (Lei 42/06 de 25 de Agosto) ou detentores de cães de "raças perigosas" (decreto-lei 315/2009 de 29 de Outubro).

Num outro plano - o da concessão de medidas flexibilizadoras da pena de prisão - muito se tem argumentado (e.g., Gonçalves \& Vieira, 2006; Moreira, 2008; Rocha, Caldeira, Miguel, \& Tavares, 2005; Santos \& Gomes, 2003) sobre a necessidade produzir critérios específicos que sirvam de referência para as respectivas tomadas de decisão e que passem além do carácter vago das indicações constantes do decreto-lei 115/2009 de 12 de Outubro. Na realidade, e embora seja um facto que no caso das saídas precárias, a medida se tem saldado por um rotundo êxito (cf. Moreira, 2008) ${ }^{6}$ também é verdade que alguns dos falhanços têm tido consequências dramáticas (e.g., Gonçalves \& Vieira, 2006) ${ }^{7}$, denotando assim uma avaliação eventualmente pouco rigorosa e discricionária na apreciação dos casos (cf. Rocha \& Miguel, 2005). Esta questão, não sendo exclusiva de Portugal, levou contudo a que noutros países se tomassem decisões para a criação de instrumentos/procedimentos de avaliação que minimizassem a arbitrariedade dos processos de

6 Não se conhece nenhum estudo entre nós que tenha medido o êxito das liberdades condicionais.

7 Bem documentados na imprensa foram os casos, entre outros, de Pedro Infante, que assassinou os pais da namorada na sua segunda saída precária em 1991, o Padre Frederico Cunha condenado por abuso sexual de menores que em 1998 aproveitou a saída precária para fugir para o Brasil, ou ainda Américo Piçarreira que cumpria pena por triplo homicídio e em 2005 não regressou na terceira saída precária, cometendo vários assaltos até ao momento em que foi recapturado. tomada de decisão e evitassem o cometimento de erros (cf. Sacau, 2008; Webster \& Hucker, 2003).

Como acabámos de constatar, a emergência de novas situações e o acentuar cada vez maior de pedidos relacionados com as problemáticas mais típicas, requer da Psicologia Forense e dos seus profissionais uma postura cada vez mais competente e irrepreensível do ponto de vista ético. Tal passa pela assunção de um conjunto de princípios orientadores da prática do perito de psicologia forense, que se estende desde a forma como procede à avaliação até ao momento em que depõe em tribunal. Assim, e como já foi assinalado por vários autores (e.g., Brodsky, 1991; Blau, 1998; Hess, 1998; Machado, 2005, 2006; Machado \& Gonçalves, 2005a,b; McGuire, 1997), importa saber em que medida o trabalho do perito de psicologia forense é, em primeiro lugar, relevante, isto é, tendo em conta uma análise de custos/benefícios, saber qual é a importância das declarações do perito na tomada de decisão por parte do juiz (aceleração, prejuízo, prorrogação, ...). Em segundo lugar, qual a necessidade que sustenta a sua intervenção, ou seja, tendo em conta o que se sabe sobre o caso (os factos), em que medida vai o perito acrescentar algo de novo, com base nos seus conhecimentos e a experiência anteriores. Em terceiro lugar, importa saber se o perito é devidamente qualificado e competente, ou seja, tendo em conta a matéria em discussão, se está o perito apto a clarificar determinados aspectos ou a elucidar o Tribunal, em suma se tem ou não competência científica e profissional para tal. E, finalmente, tendo em conta o "estado da arte" e da investigação até ao momento, o perito tem a obrigação de fazer eco das limitações dos conhecimentos, relativizando a importância do mesmo e frisando o estatuto da Psicologia como ciência capaz de avançar verdades probabilísticas e não absolutas.

\section{CONCLUSÃO}

Em Portugal, a última década do século XX foi marcada pela consolidação da Psicologia da Justiça, que se traduziu por uma expansão ao nível da oferta de formação, da investigação, da 
intervenção e, sobretudo, da disseminação do saber teórico e empírico.

Já durante o século XXI e nos anos mais recentes, a Psicologia Forense afirmou-se como um parceiro útil para as tomadas de decisão judiciais sendo esse aspecto saudado por muitos juristas da nossa praça (e.g., Carmo, 2005; Carmo, Alberto, \& Guerra, 2006). Ora, se por um lado nos podemos regozijar com este reconhecimento devemos, por outro, interrogarmo-nos se estamos à altura das exigências que nos fazem. Isto é, se temos capacidade para dar uma resposta cientificamente válida para ajudar ao esclarecimento dos factos e das questões que sobre eles pendem, nomeadamente, o "quem", o "como", o "quando" e o "porquê". Procurar essas respostas face a um caso concreto, obtém-se pela análise cuidadosa dos factos relatados, a recolha de informações em várias fontes para além do arguido ou da vítima, a administração de provas aferidas e validadas ao contexto nacional, o recurso a instrumentos de avaliação forense e a exames e provas complementares, e a partilha de dúvidas com outros profissionais informados. É um trabalho demorado, que requer conhecimento e treino específicos, que deve ser executado no seio de uma equipa e que deve ser feito sob a noção de que a Psicologia é uma ciência probabilística.

Vários processos judiciais que fizeram parangonas nos órgãos de comunicação social, quer em Portugal (e.g., "o caso Casa Pia") quer no estrangeiro (e.g., "o caso Outreau", França, 2005) mostram bem o quanto é necessário trabalhar de forma séria e cientificamente apoiada, para que não sejam cometidas "barbaridades" sob a égide de uma pseudo-ciência psicológica. Em nenhum caso, deve "a busca da verdade" toldar-nos a razão nem levar-nos a extrair indícios irrefutáveis da credibilidade da vítima ou da culpabilidade do arguido, por exemplo, através de desenhos, discursos ou conteúdos oníricos por eles fornecidos, de reduzida ou nenhuma acessibilidade à refutação científica.

Sabe-se que o melhor preditor do êxito de uma avaliação psicológica forense, é a competência e o desempenho do perito (e.g., Arce \& Fariña, 2005). É pois aí que devemos centrar os nossos esforços, para bem de alegadas vítimas e presumíveis culpados. Para bem do presente e do futuro da Psicologia Forense portuguesa.

\section{REFERÊNCIAS}

Agra, C. (1986). Projecto da psicologia transdisciplinar do comportamento desviante e auto-organizado. Análise Psicológica, IV(3/4), 311-318.

Almeida, L. S. (1993). Das respostas aos compromissos sociais dos psicólogos portugueses: Dez anos de existência da APPORT. Jornal de Psicologia, 11(1-2), 3-4.

Alves, A. M. (1979). Teoria/terapia comportamental e instituição prisional. Boletim da Administração Penitenciária e dos Institutos de Criminologia, 34, 8-116.

Arce, R., \& Fariña, F. (2005). El sistema de evaluación global (SEG) de la credibilidad del testimonio: Hacia una propuesta integradora. In R. Arce, F. Fariña, \& M. Nuevo (Eds.), Psicologia Jurídica (pp. 103-109). Santiago de Compostela: Xunta de Galicia.

Bajet \& Royo, J. (1992). La psicologia juridica: Pasado y presente de su breve historia. Anuario de Psicologia Juridica, 9-15.

Barroso, J., \& Gonçalves, R. A. (Eds.). (1992). Psicologia e intervenção social de justiça. Porto: APPORT.

Blau, T. H. (1998). The psychologist as expert witness. New York: John Wiley and Sons.

Brodsky, S. (1991). Testifying in court. Washington, DC: American Psychological Association.

Caridade, S., Machado, C., \& Gonçalves, R. A. (2006). Avaliação e intervenção em contextos de justiça: $\mathrm{O}$ exemplo da Unidade de Psicologia da Justiça da Universidade do Minho. Revista do Ministério Público, 27(106), 215-249.

Carmo, R. (2005). A prova pericial: Enquadramento legal. In R. A. Gonçalves \& C. Machado (Coords.), Psicologia Forense (pp. 33-54). Coimbra: Quarteto.

Carmo, R., Alberto, I., \& Guerra, P. (2006). O abuso sexual de menores. Uma conversa sobre justiça entre o direito e a psicologia ( $2^{\mathrm{a}}$ ed.). Coimbra: Almedina.

Castro, A. J., Martins, A. S., Machado, C., \& Gonçalves, R. A. (2006) Perícias psicológicas, sentenças judiciais: Que relação? Poster apresentado no Congresso Internacional de Psicologia Forense. Braga, Universidade do Minho, 6 e 7 de Abril. 
Costa, R. C. (1954a). A psicologia do testemunho. Scientia Ivridica, 3(11), 225-243.

Costa, R. C. (1954b). A psicologia do testemunho. Método de produção e valor psicológico da prova oral. Scientia Ivridica, 3(12), 334-350.

Fariña, F., Arce, R., \& Novo, M. (2005). Que es la psicología jurídica? In R. Arce, F. Fariña, \& M. Nuevo (Eds.), Psicologia Jurídica (pp. 9-20). Santiago de Compostela: Xunta de Galicia.

Fonseca, A. C. (Ed.). (2004). Comportamento anti-social e crime - Da infância à idade adulta. Coimbra: Almedina.

Fonseca, A. C. (Ed.). (2009). Psicologia e Justiça. Coimbra: Almedina.

Fonseca, A. C., Simões, M. R., Simões, M. C. T., \& Pinho, M. S. (Eds.). (2006). Psicologia forense. Coimbra: Almedina.

Gonçalves, R. A. (1993). Psicólogos no sistema jurídico-penal português: Situação actual e perspectivas futuras. Jornal de Psicologia 11(1-2), 8-12.

Gonçalves, R. A. (1996). Psicologia da justiça: Um longo passado para uma designação recente. Psicologia: Teoria, Investigação e Prática, 1, $207-$ 218.

Gonçalves, R. A., \& Machado, C. (Coords.). (2005). Psicologia forense. Coimbra: Quarteto.

Gonçalves, R. A., \& Vieira, S. (2006) Critérios de avaliação para a concessão de medidas flexibilizadoras da pena de prisão. Comunicação apresentada no Congresso Internacional de Psicologia Forense. Braga, Universidade do Minho, 6 e 7 de Abril.

Gonçalves, R. A., Machado, C., Sani, A., \& Matos, M. (Orgs.). (1999). Crime: Práticas e testemunhos Braga: CEEP, Universidade do Minho.

Hess, A. (1998). Accepting forensic case referrals: Ethical and professional considerations. Professional Psychology: Research and Practice, 29, 109-114.

Machado, A. P. G. (2008). Regulação do poder paternal: Impacto da perícia psicológica na decisão judicial. Dissertação de Mestrado nãopublicada. Braga: Universidade do Minho.

Machado, C. (2005). Evoluções paradigmáticas na avaliação forense. Psicologia. Teoria, Investigação e Prática, 10(1), 47-63.

Machado, C. (2006). Psicologia forense: Desenvolvimentos, cientificidade e limitações. Revista do Ministério Público, 106, 5-24.
Machado, C., \& Gonçalves, R. A. (Coords.) (2003). Violência e vítimas de crimes (vol. I - Adultos, $2^{\mathrm{a}}$ ed.). Coimbra: Quarteto.

Machado, C., \& Gonçalves, R. A. (2005a). Avaliação psicológica forense: Características, problemas técnicos e questões éticas. In R. A. Gonçalves \& C. Machado (Coords.), Psicologia Forense (pp. 1931). Coimbra: Quarteto.

Machado, C., \& Gonçalves, R. A. (2005b). O psicólogo como testemunha forense. In R. A. Gonçalves \& C. Machado (Coords.), Psicologia Forense (pp. 345351). Coimbra: Quarteto.

Machado, C., \& Gonçalves, R. A. (Coords.). (2008). Violência e vítimas de crimes (vol. II - Crianças, $3^{\mathrm{a}}$ ed. revista e aumentada). Coimbra: Quarteto.

Manita, C. (2005). Estudo preliminar de caracterização de agressores no contexto da violência conjugal. Porto: Comissão para a Igualdade e para os Direitos das Mulheres.

McGuire, J. (1997). Ethical dillemas in forensic clinical psychology. Legal and Criminological Psychology, 2, 177-192.

Moreira, J. J. S. (2008). Saída (precária) prolongada: Uma aritmética do insucesso. In J. L. Moraes Rocha (Coord.), Entre a reclusão e a liberdade (vol. II, pp. 11-58). Coimbra: Almedina.

Nicholson, R. A. (1999). Forensic assessment. In Ron Roesch, Stephen D. Hart, \& James R. P. Ogloff (Eds.), Psychology and law: The state of the discipline (pp. 121-173). New York: Kluwer Academic/Plenum Publishers.

Pina, L. (1960). Instituto de Criminologia do Porto. Resenha histórico-bibliográfica. Boletim da Administração Penitenciária e dos Institutos de Criminologia, 1, 7-74.

Rocha, J. L. M., \& Miguel, A. (2005). Não voltar... In J. L. Moraes Rocha (Coord.), Entre a reclusão e a liberdade (vol. I, pp. 159-241). Coimbra: Almedina.

Rocha, J. L. M., Caldeira, B., Miguel, A., \& Tavares, P. (2005). Motivação para o regresso. In J. L. Moraes Rocha (Coord.), Entre a reclusão e a liberdade (vol. I, pp. 101-158). Coimbra: Almedina.

Sacau, A. (2008). Análise das decisões judiciais sobre saídas precárias. Psiquiatria, Psicologia e Justiça, 2, 43-53.

Sani, A I. (2002). As crianças e a violência. Coimbra: Quarteto.

Santos, B., \& Gomes, C. (2003). A reinserção social dos reclusos. Um contributo para o debate sobre a reforma do sistema prisional. Coimbra: Observatório Permanente da Justiça Portuguesa. 
Silva, D., Barroso, J., Cóias, J. O., \& Costa, R. B. (Orgs.). (1995). Os jovens e a justiça. Lisboa: APPORT.

Soeiro, C. (1999). A selecção de pessoal no contexto da polícia de investigação criminal: Análise da problemática da delimitação de um perfil psicológico versus experiência/processo de socialização. In R. A. Gonçalves, C. Machado, A. Sani, \& M. Matos (Orgs.), Crimes: Práticas e testemunhos (pp. 217-228). Braga: CEEP, Univ. do Minho.

Webster, C. D., \& Hucker, S. J. (2003). Release decision making. Hamilton, ON: Forensic Services, St. Joseph's Healthcare.

www.inml.mj.pt

\section{RESUMO}

O presente artigo traça os contornos gerais do desenvolvimento da psicologia forense em Portugal, primeiro enquanto ramo de um campo de saber mais vasto - o da Psicologia da Justiça ou Jurídica - e mais recentemente como disciplina autónoma que tem vindo a receber cada vez mais solicitações da parte das entidades judiciais. Neste sentido são apresentados dados da prática pericial forense da Unidade de Consulta de Psicologia da Justiça da Universidade do Minho, bem como resultados de investigações recentes que atestam a aceitação da prática da avaliação forense junto de magistrados judiciais. Face aos novos desafios e ao aumento de solicitações e reforçando a necessidade de uma postura ética que salvaguarde o desempenho profissional, o autor procede a algumas recomendações que devem nortear o trabalho do perito de psicologia forense.

Palavras-chave: Competência do perito, Ética pericial, Investigação, Psicologia Forense.

\section{ABSTRACT}

This paper outlines the general features of forensic psychology in Portugal, firstly in a historical perspective and under the broader scope of Legal and Juridical Psychology, and more recently as an autonomous discipline which has been receiving more and more demands from the judicial field. Accordingly, data from the forensic practice held at the University of Minho's Unit of Psychology of Justice are presented, along with results from recent research that states the acceptance and the importance of forensic evaluation for judicial magistrates. Concerning the new challenges posed by recent legal changes in Portugal and the continuous demands from the courts, the author emphasizes the ethic issues that should guide the work of the expert on forensic psychology, in order to safeguard his professional practice and social image.

Key words: Ethics, Expert qualification, Forensic Psychology, Research. 
